\title{
Neuromedin $U$ receptor 1 expression in the rat endocrine pancreas and evidence suggesting neuromedin $U$ suppressive effect on insulin secretion from isolated rat pancreatic islets
}

\author{
PRZEMYSLAW KACZMAREK ${ }^{1}$, LUDWIK K. MALENDOWICZ², EWA PRUSZYNSKA-OSZMALEK ${ }^{1}$, \\ TATIANA WOJCIECHOWICZ ${ }^{1}$, DAWID SZCZEPANKIEWICZ ${ }^{1}$, \\ TOMASZ SZKUDELSKI ${ }^{1}$ and KRZYSZTOF W. NOWAK ${ }^{1}$
}

\begin{abstract}
${ }^{1}$ Department of Animal Physiology and Biochemistry, August Cieszkowski University of Agriculture, ${ }^{2}$ Department of Histology and Embryology, Karol Marcinkowski University of Medical Sciences, Poznan, Poland
\end{abstract}

Received May 25, 2006; Accepted July 19, 2006

\begin{abstract}
Neuromedin $\mathrm{U}(\mathrm{NmU})$ is a regulatory peptide found in significant concentrations in both the brain and gut of the rat and is named according to its ability to powerfully contract the uterus. Two types of NmU receptors were recently identified and subsequent studies evidenced $\mathrm{NmU}$ involvement in the regulation of energy homeostasis. Such a role of neuromedin $U$ suggests that a polypeptide may also be involved in the regulation of adipoinsular axis function. Therefore in the present study we examined the expression of $\mathrm{NmU}$ receptors in pancreatic islets using RT-PCR and Western blotting analysis. We also investigated the role of $\mathrm{NmU}$ in regulation of insulin secretion in vitro using isolated pancreatic islets. We have confirmed that NmUR1 but not NmUR2 is specifically expressed in isolated rat pancreatic islets. In all tested doses $(1,10,100 \mathrm{nmol} / \mathrm{l}) \mathrm{NmU}$ dosedependently decreased insulin output by isolated pancreatic islets. These inhibitory effects of $\mathrm{NmU}$ on insulin secretion may suggest the involvement of $\mathrm{NmU}$ in regulating the pancreatic branch of adipoinsular axis function. Thus, NmU can be included in that group of anorectic peptides, which are also involved in the regulation of insulin secretion.
\end{abstract}

\section{Introduction}

Neuromedins $(\mathrm{Nm})$ are a family of smooth muscle contraction stimulating peptides. Their structure and biological activity

Correspondence to: Dr Przemyslaw Kaczmarek, Department of Animal Physiology and Biochemistry, August Cieszkowski University of Agriculture, 35 Wolynska Street, 60-637 Poznan, Poland

E-mail:przekacz@au.poznan.pl

Key words: neuromedin $\mathrm{U}$, neuromedin $\mathrm{U}$ receptor 1 , insulin, pancreatic islet, rat are similar to other known neuromedins. They are commonly divided into four groups: bombesin-like $(\mathrm{NmB}, \mathrm{NmC})$, kassinin-like ( $\mathrm{NmL} /$ neurokinin $\mathrm{A}, \mathrm{NmK} /$ neurokinin $\mathrm{B})$, neurotensin-like $(\mathrm{NmN})$ and neuromedin $\mathrm{U}(\mathrm{NmU})$. $\mathrm{NmU}$ was first isolated from extracts of porcine spinal cord over 15 years ago and was named for its uterine contractile activity $(1,2)$. Two molecular forms of peptides exerting full biological activity were identified: neuromedin U-25 (NmU-25) and its cleavage product, neuromedin U-8 (NmU-8). Neuromedin U was subsequently isolated from a broad range of species including rat (3), guinea pig (4), dog (5), rabbit (6) and frog (7). Isolated peptides share the greatest homology in their Cterminal regions, which appear to be crucial for the biological action of NmU.

By means of molecular biological methods, neuromedin U mRNA expression was described in a wide variety of tissues with the highest levels of transcripts in the upper gastro-intestinal tract, including the small intestine and the stomach (8-10). A significant level of neuromedin U transcripts was also found in several endocrine tissues, e.g. thyroid, pituitary gland and pancreas (8-10).

Recently, it was shown that the previously described orphan G-protein-coupled receptors FM-3 and FM-4 are cognate receptors for NmU. FM-3, designated as NmU1R, is abundantly expressed in peripheral tissues whereas FM-4, designated as NmU2R, is expressed in specific regions of the brain (11). Activation of both $\mathrm{NmU}$ receptors results in intracellular calcium accumulation via stimulation of $G$ proteins of the Gq/11 subfamily (9-11).

Despite a variety of biological activities exerted by NmU, its general physiological relevance still remains unclear. Beside well-documented smooth muscle contractile activity $(1,2)$ neuromedin $\mathrm{U}$ increases arterial blood pressure $(12,13)$ and modifies ion transport in the intestinal tract (14). NmU has also been shown to affect the neuroendocrine system. This peptide profoundly affects the release of stress-related modulators from the anterior pituitary and adrenal glands. In the rat, $\mathrm{NmU}$ administration transiently increased circulating ACTH concentration, an effect followed by prolonged elevation of serum corticosterone levels $(15,16)$. These findings suggest the possible involvement of $\mathrm{NmU}$ in the regulation of 
the hypothalamo-pituitary-adrenal axis. Furthermore, intracerebro-ventricular NmU administration to non-fasted rats decreases food intake and weight gain $(17,18)$. Moreover, $\mathrm{NmU}$ increases locomotor activity, body temperature and heat production and may be a potent endogenous anorectic peptide, which serves as the catabolic signaling molecule in the brain (17). Moreover, recently it was reported that mice lacking the gene encoding $\mathrm{NmU}\left(\mathrm{Nmu}^{-/}\right.$mice $)$develop obesity. $\mathrm{Nmu}^{-/-}$mice showed increased body weight and adiposity, hyper-phagia, decreased locomotor activity and energy expenditure (19). Obese $\mathrm{Nmu}^{-/-}$mice developed hyperleptinemia, hyperinsulinemia, late-onset hyperglycemia and hyper-lipidemia (19).

Our earlier studies revealed the involvement of both anorectic (leptin) and orexigenic (orexin) peptides in the regulation of insulin secretion in the rat (20-22). The present study aims to investigate the possible involvement of $\mathrm{NmU}$ in the regulation of endocrine pancreas function. The NmUR1 receptor was expressed in pancreatic islets of the rat and $\mathrm{NmU}$ inhibited insulin secretion from isolated pancreatic islets.

\section{Materials and methods}

$R T$-PCR detection of $N m U$ receptors in endocrine pancreas. Total cellular RNA was extracted from freshly isolated rat pancreatic islets using the TRIzol Reagent protocol (Invitrogen, USA). Concentration and sample purity were calculated using the A $260 / 280 \mathrm{~nm}$ ratio. After isopropanol precipitation, RNA was resuspended in RNase-free water and treated with RQ1 RNase-free DNase (Promega, USA) to remove residual genomic DNA. RNA was quantified by measuring the absorbance $\left(\mathrm{A}_{260 / 280}\right)$. Only samples with a ratio $\geq 1.65$ were used. cDNA was reverse transcribed from $2 \mu \mathrm{g}$ of total RNA using the Improm RT system (Promega) and specific primers for NmU, NmUR1 and NmUR2. Primers sequences, PCR product length and annealing temperatures are presented in Table I. After a reverse transcription step $\left(48^{\circ} \mathrm{C}\right.$ for $45 \mathrm{~min}$ ) and PCR activation $\left(95^{\circ}\right.$ for $5 \mathrm{~min}$ ), the PCR conditions were as follows: 36 cycles at $95^{\circ} \mathrm{C}$ for $30 \mathrm{sec}$, specific annealing temperature for $30 \mathrm{sec}$ and $72^{\circ} \mathrm{C}$ for $1.5 \mathrm{~min}$, with a final extension step at $72^{\circ} \mathrm{C}$ for $7 \mathrm{~min}$. Control reactions were carried out without the addition of reverse transcriptase. The quality and integrity of each cDNA was assessed by the parallel amplification of the rat $\beta$-actin gene (data not shown). The PCR products were separated in $1.5 \% \mathrm{EtBr}$ agarose gel and photographed.

In order to verify NmUR1 identification, restriction analysis of PCR products was performed. Amplified DNA was eluted from EtBr agarose gel using a Perfectprep gel cleanup kit (Eppendorf, Germany), digested by Pst I (Promega, USA) restrictase and hence DNA fragments of the expected sizes were observed (Fig. 1)

Western blotting. Total proteins were isolated simultanously with RNA according to the protocol of Chomczynski and Sacchi and dissolved in $0.01 \%$ SDS (23). The aliquots containing $25 \mu \mathrm{g}$ of isolated protein were subjected to standard SDS-PAGE in a Bio-Rad apparatus (Mini-Protean). The prestained molecular mass standards (Kaleidoscope Markers, Bio-Rad, USA) were used. Semi-dry electrotransfer of proteins from the gel to PVDF membranes (Immun-Blot, Bio-Rad) was performed (30 min at $15 \mathrm{~V}$ ) in a Bio-Rad apparatus as described (24). In

Table I. Nucleotide sequences of PCR primers for NmU and NmU receptors.

\begin{tabular}{lcccr}
\hline Target & Orientation & Sequence & Product length $(\mathrm{bp})$ & Annealing temperature $\left({ }^{\circ} \mathrm{C}\right)$ \\
\hline NmUR1 & Sense & 5'-CTGGGTCTTCGCTATTCTC-3' & 327 & 55 \\
& Antisense & 5'-TGTCTGCGTTCCCTATCTC-3' & & 56 \\
NmUR2 & Sense & 5'-TGTGCTTTGCCTCCATTCTC-3' & 382 & 52 \\
& Antisense & 5'-ACAGCCACTTTGTTCGCCTC-3' & & 323 \\
NmU & Sense & 5' GCGTCCTTTCTGTCTGTTGA-3' & 32 \\
& Antisense & 5' CTTGTTGACCTCTTCCCATT-3' & & 5 \\
\hline
\end{tabular}

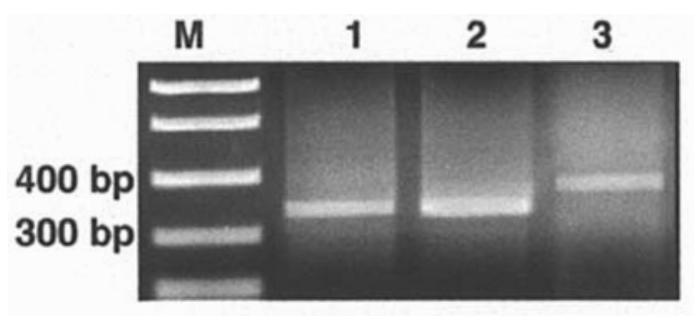

A

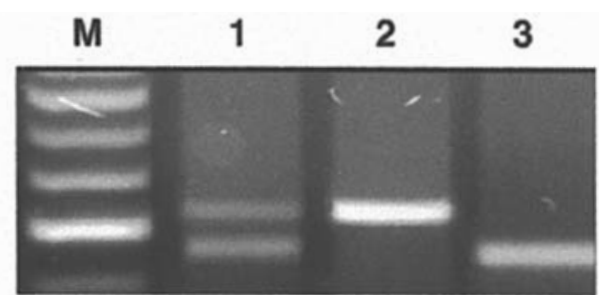

B

Figure 1. Verification of RT-PCR detection of NmUR1 for positive control (A) and amplification product restriction analyses (B). A: lane M, DNA ladder; lane 1, duodenum (NmU); lane 2, duodenum (NmUR1); and lane 3, hypothalamus (NmUR2). B: lane M, DNA ladder; lane 1, NmUR1-specific PCR product after 30 min of incubation with Pst I; lane 2, NmUR1-specific PCR product after incubation without Pst I; and lane 3, NmUR1-specific PCR product after 60 min of incubation with $P s t$ I. The PCR products were resolved in $1.5 \% \mathrm{EtBr}$ agarose 


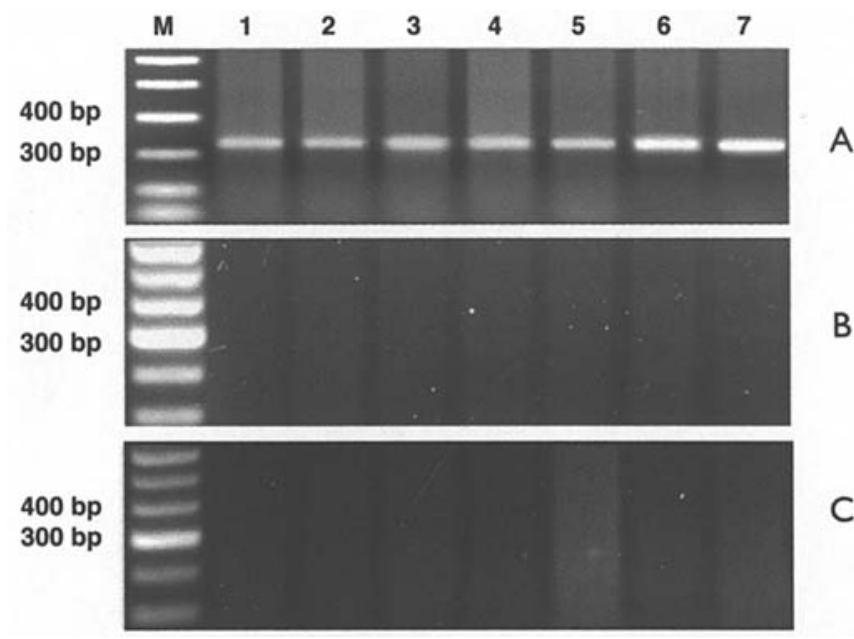

Figure 2. RT-PCR detection of NmU and its receptors: Lane M, DNA ladder; lanes 1-4, pancreatic islets; and lanes 5-7, whole pancreas. Panel A, NmUR1-specific primers; panel B, NmUR2-specific primers; and panel C, $\mathrm{NmU}$-specific primers. The PCR products were resolved in $1.5 \% \mathrm{EtBr}$ agarose.

order to verify transfer efficiency, the immobilized proteins were reversibly stained in Ponceau S solution. Non-specific protein binding was reduced during overnight incubation with Blotto A buffer. The membranes were subsequently incubated with specific rabbit antibodies, anti-rat NmUR1 and NmUR2 respectively (Alpha Diagnostic International, San Antonio, Texas, USA) and washed with TBST. Immunoreactive complexes were detected with secondary, anti-rabbit immunoglobulins, conjugated to horseradish peroxidase and SuperSignal West Dura kit (Pierce, USA). Western blots were visualized using a Typhoon apparatus (Pharmacia, USA) (Fig. 3).

Pancreatic islet isolation and incubation with $\mathrm{NmU}$. Pancreas taken from three male Wistar rats weighing 250-
$290 \mathrm{~g}$ were cut into small pieces and islets were isolated by collagenase digestion according to the method of Lacy and Kostianovsky (25). During isolation, Hank's solution saturated with $95 \% \mathrm{O}_{2}$ and $5 \% \mathrm{CO}_{2}$ was used. After the digestion, islets were separated from the remaining nonendocrine tissue by hand picking under a stereomicroscope. Groups of five islets were then incubated for $90 \mathrm{~min}$ in $1 \mathrm{ml}$ of Krebs-Ringer bicarbonate buffer containing $0.5 \% \mathrm{BSA}$ (fraction $\mathrm{V}$, fatty acid-free) and $6.7 \mathrm{mM}$ glucose at $37^{\circ} \mathrm{C}$ and $\mathrm{pH} 7.4$ with or without $\mathrm{NmU}$. NmU was used at three concentrations: 1,10 and $100 \mathrm{nM}$. Incubations were performed in an atmosphere of $95 \% \mathrm{O}_{2}$ and $5 \% \mathrm{CO}_{2}$. At the end of the incubations, aliquots of the medium were stored at $-20^{\circ} \mathrm{C}$ until insulin concentrations were measure. The influence of $\mathrm{NmU}$ on insulin secretion by isolated pancreatic islets was examined in two separate experiments ( $\mathrm{n}=3$ in each experiment).

Hormone assays. Insulin in the perfusion/incubation medium was assayed radioimmunologically using a commercially available kit for rat insulin (Rat insulin RIA kit, Linco Research Inc., St. Charles, MO, USA). Intra and interassay variations were $5 \%$ and $7 \%$, respectively.

Statistical analysis. Results were averaged per experimental group and the SEM, was calculated. Statistical comparison of the data was made by ANOVA followed by the Multiple Range Test of Duncan.

\section{Results}

RT-PCR results suggest that NmUR1, but not NmUR2 is expressed in rat pancreatic islets (Fig. 2). We encountered no evidence for unique neuromedin $U$ transcription in pancreatic endocrine cells (Fig. 2). To verify the specificity of the PCR, the DNA product corresponding to the NmUR1 was digested with specific restriction enzymes and fragments of the expected size were obtained (Fig. 1). Moreover, the PCR

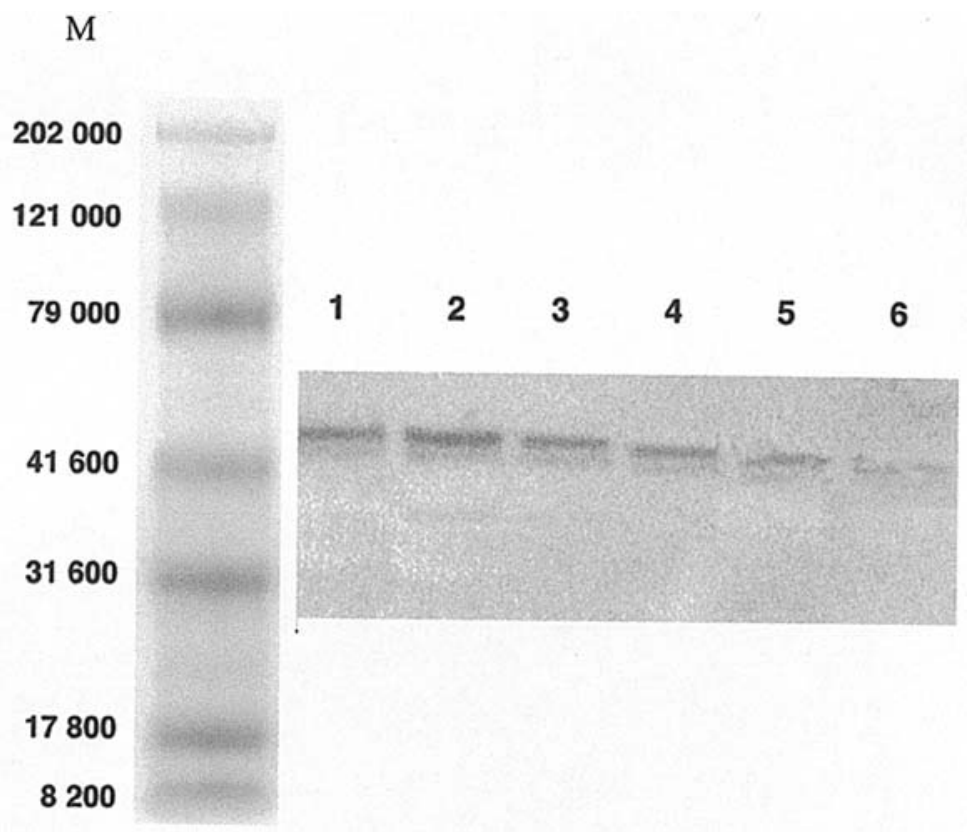

Figure 3. Immunodetection of NmUR1. Lane M, BioRad Kaleidoscope marker (BioRad); lanes 1-4, pancreatic islets; and lanes 5-6, whole pancreas. 


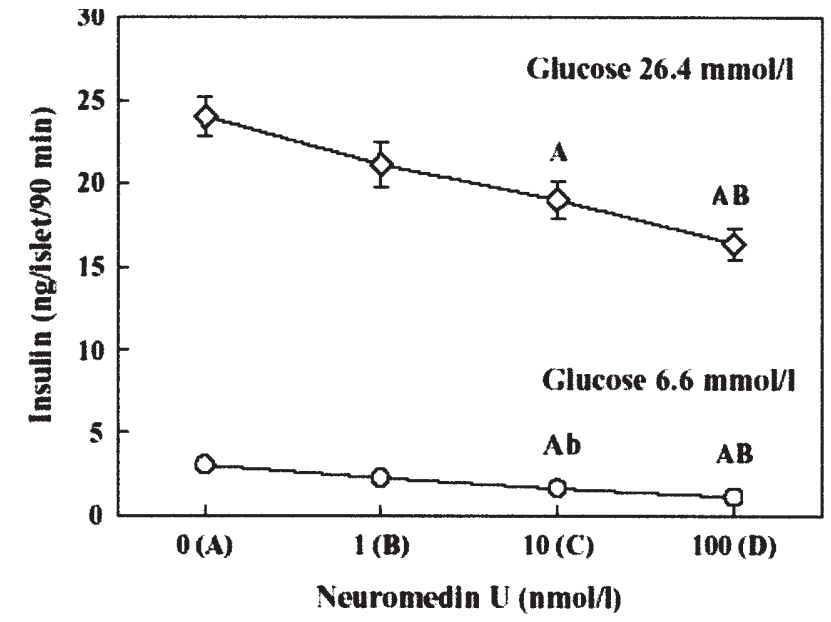

Figure 4. The effect of $\mathrm{Nm} \mathrm{U}(1,10$ or $100 \mathrm{nmol} / \mathrm{l})$ on insulin release from isolated pancreatic islets stimulated by physiological $(6.6 \mathrm{mmol} / \mathrm{l})$ and supraphysiological $(26.4 \mathrm{mmol} / \mathrm{l})$ glucose concentrations. The mean from two separate experiments ( $\mathrm{n}=6$ in each experiment) and SEM are shown. Statistically significant differences are marked with letters corresponding to the marked group (lower case, $\mathrm{p}<0.05$; capitals, $\mathrm{p}<0.01$ ).

findings were thoroughly upheld on protein level by Western blotting (Fig. 3).

The in vitro investigations with isolated pancreatic islets incubated with increasing concentrations of $\mathrm{NmU}$ (1, 10 and $100 \mathrm{nmol} / \mathrm{l}$ ) revealed a direct neuropeptide action on endocrine pancreatic cells. Data clearly demonstrate a dose-dependent inhibitory effect of $\mathrm{NmU}$ on insulin output by isolated rat pancreatic islets (Fig. 4). In the performed experiments a significant drop of insulin secretion was trigger by $10 \mathrm{nM}$ and $100 \mathrm{nM} \mathrm{NmU}$. A similar insulinostatic effect of neuromedin $\mathrm{U}$ was observed in the case of physiological $(6.6 \mathrm{mmol} / \mathrm{l})$ and supraphysiological $(26.4 \mathrm{mmol} / \mathrm{l})$ glucose concentrations. As demonstrated, the inhibitory effect of $\mathrm{NmU}$ on insulin secretion by isolated pancreatic islets was more marked in the presence of higher glucose concentrations (26.4 mmol/l) in the incubation medium.

\section{Discussion}

The recent identification of $\mathrm{NmU}$ receptors in a variety of peripheral tissues as well as in the central nervous system stimulated numerous extensive studies on the physiologic role of NmU. Since plasma NmU levels in the rat seem fairly low, it has been proposed that neuromedin $U$ acts as a neurotransmitter or neuromodulator rather than a circulating hormone (3). In this regard, one of the most exciting findings was the demonstration of potent procatabolic and anorectic properties of $\mathrm{NmU}$ which might be involved in the regulation of energy homeostasis at the hypothalamic level $(17,18)$.

Insulin is one of the most important hormones responsible for energy homeostasis and it is not unreasonable to suggest that $\mathrm{NmU}$ may also affect insulin secretion in the pancreatic islets. Regarding such a possibility, until now there has been no evidence for $\mathrm{NmU}$ receptor expression in endocrine pancreas. Recently, a number of investigators demonstrated the presence of NmUR1 mRNA in the pancreas, with transcript levels equivalent to that seen in other regions of the gastrointestinal tract. However, the anatomical localization of that receptor in a particular component of the pancreas remained unknown. Sumi et al (13) demonstrated increased pancreatic blood flow after $\mathrm{NmU}$ administration, a finding that suggests vascular localization of NmUR1 (11). Results of our RT-PCR studies are the first to demonstrate the presence of NmUR1 in the rat endocrine pancreas. Moreover, immunodetection revealed the presence of receptor protein in extracts from pancreatic islets. Thus, NmUR1 expression in the pancreas is not restricted to exocrine pancreas or gland vasculature and such localization suggests the possibility of direct NmU influence on the endocrine functions of the gland.

Results of our in vitro experiments apparently confirm this hypothesis. For the first time we demonstrated that $\mathrm{NmU}$ in higher doses $(10$ and $100 \mathrm{nmol} / \mathrm{l})$ significantly inhibits insulin secretion from isolated pancreatic islets. These findings also exclude the possibility that $\mathrm{NmU}$ evoked changes in insulin secretion may be dependent on alterations in pancreatic blood flow. Moreover, in our in vitro experiments $\mathrm{NmU}$ concentrations were comparable to that seen in normal circulation. The significant expression of $\mathrm{NmU}$ in the pancreas $(9,11)$ and closely situated GI tract, combined with the presence of NmUR1 in the endocrine part of the pancreas strongly implies a paracrine action of $\mathrm{NmU}$ on insulin secretion in the rat. As demonstrated, NmUR1 activation leads to a dose-dependent release of intracellular $\mathrm{Ca}^{2+}(8-11)$. Furthermore, intra-cellular calcium influx is one of the major factors responsible for the stimulation of insulin secretion from pancreatic $\beta$ cells. However, in our in vitro experiments $\mathrm{NmU}$ generates an opposite, insulinostatic effect. This rather unexpected and puzzling effect may be explained by different expression of NmUR1 on particular cell types of the pancreatic islet. Therefore, the results may indicate that the observed NmU action on the endocrine pancreas is not directly connected with signal transduction via NmUR1 receptors in $\beta$ cells. One of the hypothetical explanations of this phenomenon might be NmUR1 presence in the pancreatic $\delta$ cells. In this case, the NmU stimulated somatostatin release could be directly responsible for the observed inhibition in insulin secretion.

The inhibitory action of $\mathrm{NmU}$ on insulin secretion corresponds in general with postulated strong procatabolic and anorectic properties of $\mathrm{NmU}(17,18)$. However, in earlier reports $\mathrm{NmU}$ action in the regulation of energy homeostasis was restricted to CNS localized events. On the other hand, the NmU receptors are abundantly expressed outside of CNS and the results of our studies suggest that peripheral $\mathrm{NmU}$ receptors may also be involved in regulation of energy homeostasis. In view of these findings it seems reasonable to suggest that $\mathrm{NmU}$ effects on feeding behavior may be mediated by both central and peripheral $\mathrm{NmU}$ receptors.

\section{Acknowledgments}

Results presented in this study were in part incorporated into the Ph.D. thesis of P. Kaczmarek.

\section{References}

1. Minamino N, Kangawa K and Matsuo H: Neuromedin U-8 and U-25: novel uterus stimulating and hypertensive peptides identified in porcine spinal cord. Biochem Biophys Res Commun 130: 1078-1085, 1985. 
2. Minamino N, Sudoh T, Kangawa $\mathrm{K}$ and Matsuo H: Neuromedins: Novel smooth-muscle stimulating peptides identified in porcine spinal cord. Peptides 6 (Suppl 3): 245-248, 1985.

3. Domin J, Ghatei MA, Chohan P and Bloom SR: Neuromedin U - a study of its distribution in the rat. Peptides 8: 779-784, 1987.

4. Murphy R, Turner CA, Furness JB, Parker L and Giraud A: Isolation and microsequence analysis of a novel form of neuromedin $U$ from guinea pig small intestine. Peptides 11: 613-617, 1990.

5. O'Harte F, Bockman CS, Abel PW and Conlon JM: Isolation, structural characterization and pharmacological activity of dog neuromedin U. Peptides 12: 11-15, 1991.

6. Kage R, O'Harte F, Thim L and Conlon JM: Rabbit neuromedin U-25: lack of conservation of a posttranslational processing site. Regul Pept 33: 191-198, 1991.

7. Salmon AL, Johnsen AH, Bienert M, et al: Isolation, structural characterization, and bioactivity of a novel neuromedin $U$ analog from the defensive skin secretion of the Australasian tree frog, Litoria caerulea. J Biol Chem 275: 4549-4554, 2000.

8. Szekeres PG, Muir AI, Spinage LD, et al: Neuromedin U is a potent agonist at the orphan G protein-coupled receptor FM3. J Biol Chem 275: 20247-20250, 2000.

9. Hedrick JA, Morse K, Shan L, et al: Identification of a human gastrointestinal tract and immune system receptor for the peptide neuromedin U. Mol Pharmacol 58: 870-875, 2000.

10. Fujii R, Hosoya M, Fukusumi S, et al: Identification of neuromedin $\mathrm{U}$ as the cognate ligand of the orphan $\mathrm{G}$ proteincoupled receptor FM-3. J Biol Chem 275: 21068-21074, 2000.

11. Raddatz R, Wilson AE, Artymyshyn R, et al: Identification and characterization of two neuromedin $\mathrm{U}$ receptors differentially expressed in peripheral tissues and the central nervous system. J Biol Chem 275: 32452-32459, 2000.

12. Gardiner SM, Compton AM, Bennett T, Domin J and Bloom SR: Regional hemodynamic effects of neuromedin $U$ in conscious rats. Am J Physiol 258: R32-R38, 1990.

13. Sumi S, Inoue K, Kogire M, et al: Effect of synthetic neuromedin U-8 and U-25, novel peptides identified in porcine spinal cord, on splanchnic circulation in dogs. Life Sci 41: 1585-1590, 1987.
14. Brown DR and Quito FL: Neuromedin U octapeptide alters ion transport in porcine jejunum. Eur J Pharmacol 155: 159-162, 1988.

15. Malendowicz LK, Nussdorfer GG, Markowska A, Tortorella C, Nowak M and Warchol JB: Effects of neuromedin U (NMU)-8 on the rat hypothalamo-pituitary-adrenal axis. Evidence of a direct effect of NMU-8 on the adrenal gland. Neuropeptides 26: 47-53, 1994.

16. Malendowicz LK, Nussdorfer GG, Nowak KW and Mazzocchi G Effects of neuromedin U-8 on the rat pituitary-adrenocortical axis. In Vivo 7: 419-422, 1993.

17. Nakazato M, Hanada R, Murakami N, et al: Central effects of neuromedin $U$ in the regulation of energy homeostasis. Biochem Biophys Res Commun 277: 191-194, 2000.

18. Howard AD, Wang R, Pong SS, et al: Identification of receptors for neuromedin $U$ and its role in feeding. Nature 406: 70-74, 2000.

19. Hanada R, Teranishi H, Pearson JT, et al: Neuromedin U has a novel anorexigenic effect independent of the leptin signaling pathway. Nat Med 10: 1067-1073, 2004.

20. Switonska MM, Kaczmarek P, Malendowicz LK and Nowak KW: Orexins and adipoinsular axis function in the rat. Regul Pept 104: 69-73, 2002.

21. Nowak KW, Mackowiak P, Switonska MM, Fabis M and Malendowicz LK: Acute orexin effects on insulin secretion in the rat: in vivo and in vitro studies. Life Sci 66: 449-454, 2000.

22. Nowak KW, Mackowiak P, Nogowski L, Szkudelski T and Malendowicz LK: Acute leptin action on insulin blood level and liver insulin receptor in the rat. Life Sci 63: 1347-1352, 1998.

23. Chomczynski P and Sacchi N: Single-step method of RNA isolation by acid guanidinium thiocyanate-phenol-chloroform extraction. Anal Biochem 162: 156-159, 1987.

24. Towbin H, Staehelin T and Gordon J: Electrophoretic transfer of proteins from polyacrylamide gels to nitrocellulose sheets: procedure and some applications. Proc Natl Acad Sci USA 76: $4350-4354,1979$

25. Lacy PE and Kostianovsky M: Method for the isolation of intact islets of Langerhans from the rat pancreas. Diabetes 16: 35-39, 1967. 